\title{
RENAL FUNCTION IN THE SEPARATE KIDNEYS OF MAN. I. HEMODYNAMICS AND EXCRETION OF SOLUTE AND WATER IN NORMAL SUBJECTS *
}

\author{
By WILliaM H. HULET, $\dagger$ DAVID S. BALDWIN, ALBERT W. BIGGS $\ddagger$ ERVIN A. \\ GOMBOS $\ddagger$ AND HERBERT CHASIS
}

\author{
(From the Department of Medicine, New York University College of Medicine, and the Third \\ (New York University) Medical Division, Bellevue Hospital, New York, N. Y.)
}

(Submitted for publication July 8, 1959; accepted October 19, 1959)

We are presenting here an evaluation of the functional capacity of the separate kidneys in subjects without cardiovascular renal disease, as background for a similar study of patients with essential hypertension (1).

\section{METHODS}

Observations have been made in 17 normotensive subjects selected from the wards of the Third (New York University) Medical Division of Bellevue Hospital. Included in this report are observations made on 4 additional subjects reported in a previous communication (2). The total group comprises 19 female and 2 male subjects between the ages of 20 and 68 years. All subjects were maintained on the regular hospital diet. Fluids were withheld for 15 hours and the test was performed in the morning on the fasting patients.

After local anesthesia with 2 per cent metycaine, cystoscopy and ureteral catheterization were performed, employing Pederson multi-eyed ureteral catheters inserted to a distance of 12 to $16 \mathrm{~cm}$. Large diameter catheters (no. 8 through no. $6 \mathrm{Fr}$.) were utilized to minimize leakage. 1 A soft rubber catheter was placed in the bladder to detect leakage around the ureteral catheters. In none of the observations reported here did measurable leakage occur. If leakage does occur, analysis of bladder urine permits partition between the right and left kidneys if the concentrations of the test substances are

* This investigation was supported in part by funds from the Abraham S. Birsh Fellowship Fund, the Joseph Laffan Morse Foundation and Grants H-3272 and H-1172 from the National Heart Institute, Bethesda, Md.

† Research Fellow, The American Heart Association.

$\ddagger$ Research Fellow, The New York Heart Association.

${ }^{1}$ In subject J.K. (Table I), it was not possible to pass the right ureteral catheter; therefore, with the left catheter in place, the bladder was used for collection from the right kidney. These conditions are not favorable for reliable collection of urine from the separate kidneys since it is possible that the bladder specimen contains urine that has leaked from the catheterized ureter. When this manner of urine collection is unavoidable, a small amount of indigo carmine can be injected into the ureteral catheter in order to detect leakage. different in the urine from the separate kidneys. The origin of the bladder urine cannot be determined when the concentrations are equal.

All individuals were given $100 \mathrm{mg}$ of sodium pentobarbital intramuscularly 30 minutes prior to cystoscopy. In some instances, the barbiturate was supplemented at the time of cystoscopy by the administration of 25 to 50 $\mathrm{mg}$ of meperidine hydrochloride intravenously or 75 to $100 \mathrm{mg}$ intramuscularly. Surgical sterility was maintained throughout the procedure. An antibiotic, either streptomycin or tetracycline, was sometimes administered for 24 to 48 hours preceding the test, and an antibiotic was invariably administered for 72 hours following the test.

Satisfactory flow from both ureteral catheters was usually attained within 15 to 20 minutes after catheterization. Timed urine samples were then collected for the determination of basal sodium, solute and water excretion. After injection of suitable priming doses of inulin (IN) and $p$-aminohippurate (PAH), a sustaining infusion of these test substances dissolved in distilled water or in 0.85 per cent sodium chloride was administered at a rate of $2 \mathrm{ml}$ per minute.

Urine and appropriately timed venous blood samples were collected during 1,2 or 3 periods totaling 30 to 40 minutes for the determination of glomerular filtration rate $\left(C_{I N}\right)$, renal plasma flow $\left(C_{P A B}\right)$ and sodium, solute and water excretion. This was followed by determination of the maximal tubular excretory capacity for $p$-aminohippurate $\left(\mathrm{Tm}_{\mathrm{PAH}}\right)(3)$.

Inulin was determined by a modification of Harrison's method (4) and PAH by the method of Smith and associates (5). Osmolality of plasma and urine was determined by means of a thermistor bridge-null-point-detector unit, using a Johlin freezing point apparatus (6). Flame photometry employing lithium as an internal standard was used for sodium determinations.

Calculation of derived data. The per cent contribution of sodium and its attendant anions to the total osmolality of the urine was calculated from the osmotic coefficient of sodium chloride, $i$ (7), for each urine sodium concentration :

$$
\text { Per cent }=\frac{\mathrm{U}_{\mathrm{Na}} i}{\mathrm{U}_{\mathrm{osm}}} \times 100,
$$

where $U_{\mathrm{Na}}$ is the urine sodium concentration in milli- 
equivalents per liter of urine, and $U_{o s m}$ is the urine solute concentration in milliosmoles per kilogram of water. ${ }^{2}$

Excretion fraction (EF) of sodium or total solute is the percentage of the filtered load excreted in the urine:

$$
\begin{aligned}
& E F_{\mathrm{Na}}=\frac{\mathrm{U}_{\mathrm{Na}} \mathrm{V}}{\mathrm{P}_{\mathrm{Na}} \mathrm{C}_{\mathrm{IN}}} \times 100, \\
& \mathrm{EF}_{\text {osm }}=\frac{\mathrm{U}_{\text {osm }} \mathrm{V}}{\mathrm{P}_{\text {osm }} \mathrm{C}_{\mathrm{IN}}} \times 100,
\end{aligned}
$$

where $\mathrm{V}$ is the urine volume in milliliters per minute, $\mathrm{P}_{\mathrm{Na}}$ is the sodium concentration in milliequivalents per liter of plasma and $P_{\text {osm }}$ and $U_{o s m}$ are the respective plasma and urine solute concentrations in milliosmoles per kilogram of water.

The differences between the right and left kidneys were calculated by dividing the difference, $\Delta$, by the mean value for the two kidneys, yielding a per cent difference relative to this mean:

Per cent difference $=\frac{\Delta}{\frac{\mathrm{R}+\mathrm{L}}{2}} \times 100$ or $\frac{2 \Delta}{\mathrm{R}+\mathrm{L}} \times 100$.

The per cent difference, rather than the absolute difference, was chosen because it permits comparison of various functions in the two kidneys at different absolute values of these functions without identifying either kidney as normal or abnormal.

It is conventional to define "normality" by recourse to probability theory and the use of parametric statistical analysis (mean \pm standard deviation), but the parametric method has the disadvantage that it is applicable only when the frequency distribution curve approaches the symmetrical or Gaussian form. Since this curve is markedly skewed when an analysis is made of increasing variation between two positive terms, such as differences between the two kidneys, parametric analysis yields negative (and physiologically meaningless) values at mean \pm 2 standard deviations. A mathematically more appropriate analysis is available in the nonparametric percentile method which permits analysis of increasing variation between any two positive terms until one term becomes zero (8). Therefore, we have used the nonparametric percentile method in our analysis of the functional differences between the two kidneys. In addition, however, the same data were analyzed by the conventional parametric method (mean \pm standard deviation) (8).

By any method of statistical analysis, wholly arbitrary limits must be set beyond which "normal" variation passes into the "abnormal," even when comparing the differences

\footnotetext{
2 Because urine flow was measured in milliliters per minute rather than in grams of water per minute, these and later calculations must neglect the difference between osmolal ( $i, P_{o s m}$ and $U_{o s m}$ ) and osmolar ( $\left.U_{\mathrm{Na}_{\mathrm{a}}}\right)$ concentrations; at physiological concentrations the error thereby introduced is negligible. The error is, however, larger in Equation 3, but may be neglected for our present purposes, especially since we are comparing urine composition between the two kidneys.
}

between the two kidneys of normotensive subjects. Accordingly, we have arbitrarily identified differences between the two kidneys below the top ninetieth percentile group in variation as normal (or for clinical purposes, as identical). Differences above the ninetieth percentile group, i.e., that 10 per cent of the group which shows the greatest per cent differences, are arbitrarily designated as not identical, or abnormal. This exclusion at the ninetieth percentile is statistically comparable to exclusion beyond the limits: mean \pm 1.6 standard deviations. Rather than use the term "abnormal," however, we will refer to the ninetieth percentile group in variation by the noncommital term "disparate," which is to be set against the clinically convenient terms "identical" or "equal."

For describing glomerular filtration rate (GFR), renal plasma flow (RPF) and $\mathrm{Tm}_{\mathrm{PAB}}$ bilaterally (right plus left or $R+L$ ), as well as in all derived ratios, we have used the arithmetic means of these values.

\section{RESULTS AND DISCUSSION}

Function in the two kidneys in this series of 21 subjects is identical, by our arbitrary definition, in 16 individuals. Tables I and II give the specific functions studied and the differences expressed as percentages. Table III gives the data pertinent to nonparametric analysis, the last column showing the maximal per cent difference at the ninetieth percentile cutoff level. Table IV gives the data on all subjects analyzed by the parametric method.

The advantage of setting arbitrary limits for identical function on the two sides lies in the fact that it invites detailed examination of the most highly aberrant values. It is noteworthy in this respect that all disparities in function beyond the ninetieth percentile levels occur in the same five subjects. $^{3}$ In two of these five subjects, C.K. and A.D., the left kidney showed proportionately greater GFR, and sodium and total solute excretion, suggesting that this left kidney was larger than the right, an interpretation in conformity with known differences in kidney weight $(9,10)$. In D.E., despite equal values of $\mathrm{V}$, disparately small values of $U_{\mathrm{Na}}$ and $U_{\text {osm }}$ coincided with small values of GFR, $R P F$ and $\mathrm{Tm}_{\mathrm{PAB}}$ on the right side, suggesting either unilateral or bilateral disease with unequal impairment in function. In a fourth subject, J.K., $U_{\mathrm{Na}}$ and $U_{\text {osm }}$ were disparately low on the right side although all other functions were identical. In the fifth subject, M.H., a difference

3 In a sixth subject, K.M., disparity in $U_{N a}$ at small values of this term was not considered significant. 

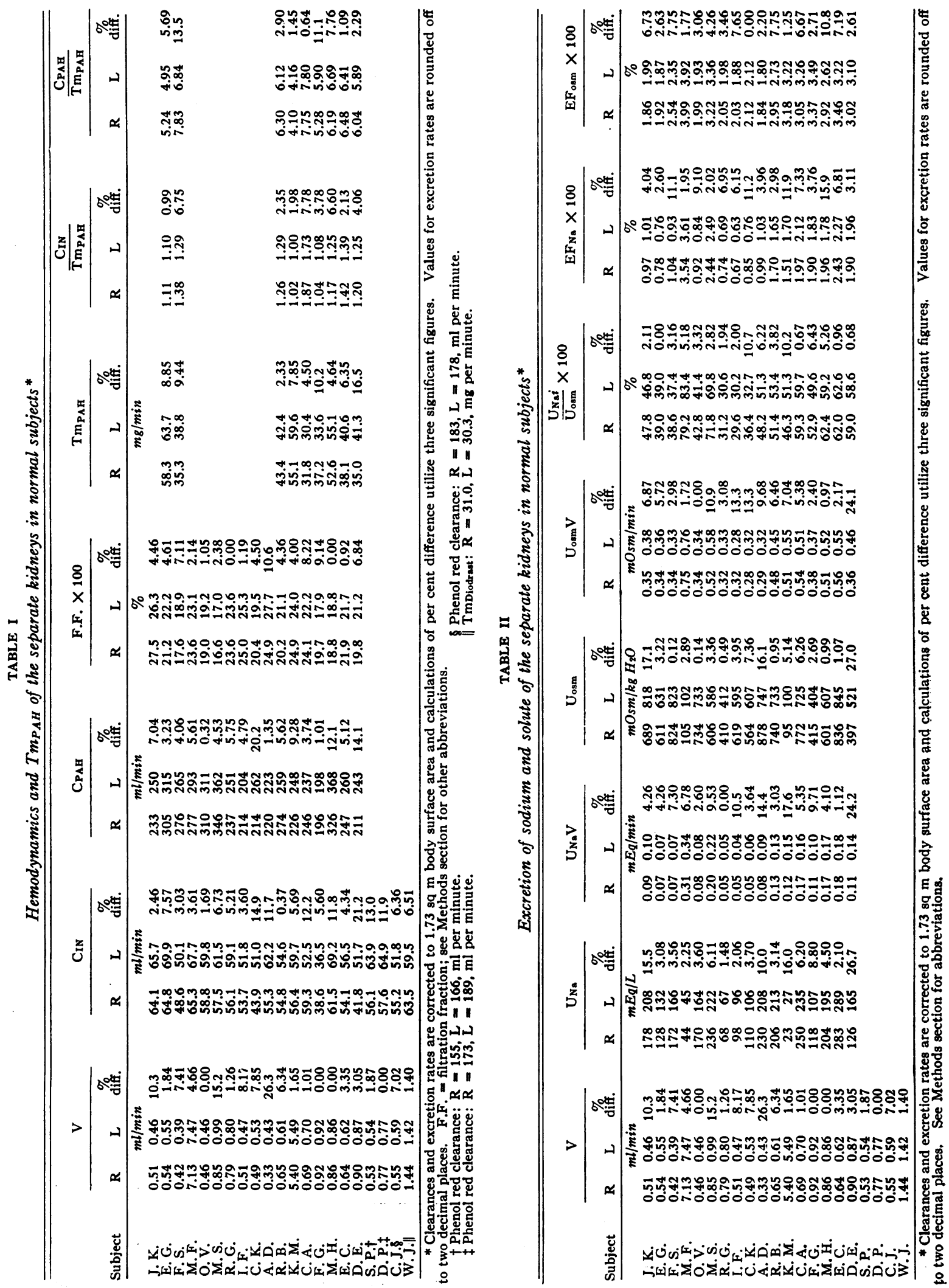
TABLE III

Per cent differences in functions of the separate kidneys in normal subjects*

\begin{tabular}{|c|c|c|c|c|}
\hline Function & $\mathbf{n}$ & $\begin{array}{c}\text { Range } \\
\text { per cent } \\
\text { difference }\end{array}$ & $\begin{array}{c}\text { Median } \\
\text { per cent } \\
\text { difference }\end{array}$ & $\begin{array}{c}\text { 90th } \\
\text { Percentile } \\
\text { per cent } \\
\text { difference }\end{array}$ \\
\hline $\begin{array}{c}\mathrm{C}_{\mathrm{IN}} \\
\mathrm{C}_{\mathrm{PAH}} \\
\text { F. } \\
\underset{\text { TmPAH }}{\mathrm{T}} \times 100\end{array}$ & $\begin{array}{r}21 \\
17 \\
17 \\
9\end{array}$ & $\begin{array}{l}0.37-21.2 \\
0.32-20.2 \\
0.00-10.6 \\
2.33-16.5\end{array}$ & $\begin{array}{l}6.36 \\
5.12 \\
4.36 \\
7.85\end{array}$ & $\begin{array}{c}13.0 \\
12.1 \\
8.22 \\
10.2\end{array}$ \\
\hline$\frac{\mathrm{C}_{\mathrm{IN}}}{\mathrm{Tm}_{\mathrm{PAB}}}$ & 9 & $0.99-7.78$ & 3.78 & 6.75 \\
\hline$\frac{\mathrm{C}_{\text {PAH }}}{\mathrm{Tm}_{\mathrm{PAB}}}$ & 9 & $0.64-13.5$ & 2.90 & 11.1 \\
\hline $\begin{array}{l}\mathrm{V} \\
\mathrm{U}_{\mathrm{Na}} \\
\mathrm{U}_{\mathrm{Na}} \mathrm{V} \\
\mathrm{U}_{\text {oam }} \\
\mathrm{U}_{\text {osm }} \mathrm{V}\end{array}$ & $\begin{array}{l}21 \\
17 \\
17 \\
17 \\
17\end{array}$ & $\begin{array}{l}0.00-26.3 \\
1.48-26.7 \\
0.00-24.2 \\
0.12-27.0 \\
0.00-24.1\end{array}$ & $\begin{array}{l}3.05 \\
3.70 \\
5.35 \\
3.22 \\
5.72\end{array}$ & $\begin{array}{l}10.3 \\
15.5 \\
14.4 \\
16.1 \\
13.3\end{array}$ \\
\hline$\frac{\mathrm{U}_{\mathrm{Na}} i}{\mathrm{U}_{\mathrm{ogm}}} \times 100$ & 17 & $0.00-10.7$ & 3.16 & 6.43 \\
\hline $\begin{array}{r}\mathrm{EF}_{\mathrm{Na}} \\
\mathrm{EF}_{\text {odm }}\end{array} \times 100$ & $\begin{array}{l}17 \\
17\end{array}$ & $\begin{array}{l}1.95-15.9 \\
0.00-10.8\end{array}$ & $\begin{array}{l}6.15 \\
3.46\end{array}$ & $\underset{7.75}{11.2}$ \\
\hline
\end{tabular}

* See Methods section for abbreviations.

in GFR accompanied by identical $\mathrm{U}_{\mathrm{Na}} \mathrm{V}$ and $\mathrm{U}_{\text {osm }} \mathrm{V}$ resulted in disparity in $\mathrm{EF}_{\mathrm{Na}}$ and $\mathrm{EF}_{\mathrm{osm}}$.

When disparities are found in apparently normal individuals, these may represent the extremes of normal variation, the inclusion of subjects with renal disease, or an effect of instrumentation, i.e., reflex responses or partial obstruction of urine flow by clots or edema of ureteral mucosa.

TABLE IV

Parametric statistical analysis of differences in functions of the separate kidneys in normal subjects*

\begin{tabular}{|c|c|c|c|c|}
\hline Function & $\mathbf{n}$ & $\begin{array}{c}\text { Range } \\
\text { per cent } \\
\text { difference }\end{array}$ & $\begin{array}{c}\text { Mean } \\
\text { per cent } \\
\text { difference }\end{array}$ & $\begin{array}{l}\text { Standard } \\
\text { deviation }\end{array}$ \\
\hline 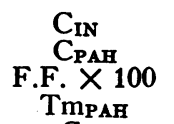 & $\begin{array}{r}21 \\
17 \\
17 \\
9\end{array}$ & $\begin{array}{l}0.37-21.2 \\
0.32-20.2 \\
0.00-10.6 \\
2.33-16.5\end{array}$ & $\begin{array}{l}7.59 \\
6.34 \\
4.21 \\
7.85\end{array}$ & $\begin{array}{l}5.04 \\
4.94 \\
3.16 \\
3.92\end{array}$ \\
\hline$\frac{\mathrm{C}_{\text {IN }}}{\operatorname{Tm}_{\mathrm{PAB}}}$ & 9 & $0.99-7.78$ & 4.05 & 2.30 \\
\hline$\frac{\mathrm{C}_{\text {PAB }}}{T_{\text {mPAH }}}$ & 9 & $0.64-13.5$ & 5.16 & 4.42 \\
\hline $\begin{array}{l}\mathrm{U}_{\mathrm{Na}} \\
\mathrm{U}_{\mathrm{Na}} \mathrm{V} \\
\mathrm{U}_{\text {osm }} \\
\mathbf{U}_{\text {osm }} \mathrm{V}\end{array}$ & $\begin{array}{l}21 \\
17 \\
17 \\
17 \\
17\end{array}$ & $\begin{array}{l}0.00-26.3 \\
1.48-26.7 \\
0.00-24.2 \\
0.12-27.0 \\
0.00-24.1\end{array}$ & $\begin{array}{l}5.18 \\
6.99 \\
7.55 \\
5.81 \\
6.83\end{array}$ & $\begin{array}{l}6.16 \\
6.53 \\
6.14 \\
7.20 \\
5.87\end{array}$ \\
\hline$\frac{\mathrm{U}_{\mathrm{Na}} i}{\mathrm{U}_{\mathrm{osm}}} \times 100$ & 17 & $0.00-10.7$ & 3.85 & 3.06 \\
\hline $\begin{array}{r}E F_{\mathrm{Na}} \\
\mathrm{EF}_{\mathrm{osm}}\end{array} \times 100$ & $\begin{array}{l}17 \\
17\end{array}$ & $\begin{array}{l}1.95-15.9 \\
0.00-10.8\end{array}$ & $\begin{array}{l}6.52 \\
4.62\end{array}$ & $\begin{array}{l}4.24 \\
2.91\end{array}$ \\
\hline
\end{tabular}

* See Methods section for abbreviations.
Anatomical studies of kidney weight and size and roentgenographic measurements indicate that the two kidneys are approximately equal, although the mean values are larger for the left kidney $(9,10)$. Our physiologic observations agree with these data in that the average values of GFR, RPF, $\mathrm{Tm}_{\mathrm{PAH}}, \mathrm{U}_{\mathrm{Na}} \mathrm{V}$ and $\mathrm{U}_{\mathrm{Osm}} \mathrm{V}$ are greater for the left kidney than for the right. ${ }^{4}$ One consequence of a consistent difference in function in respect to GFR and $\mathrm{Tm}_{\mathrm{PAB}}$ is that the derived values of GFR/ $\mathrm{Tm}_{\mathrm{PAH}}$ are the same on both sides. Although most of the individuals in this study were females, the available evidence $(9,10)$ indicates that the relative magnitude of difference in size and function between the two kidneys is similar in the two sexes.

Our bilateral measurements (calculated as $\mathrm{R}+$ L) for GFR agree with the reported average for females determined by bladder catheterization ( $\mathrm{R}+\mathrm{L}, 114$; bladder, $109 \mathrm{ml}$ per minute) (3). Our lower RPF ( $\mathrm{R}+\mathrm{L}, 524$; bladder, $592 \mathrm{ml}$ per minute) and increased filtration fraction (21.7 as calculated for each kidney; bladder, 19.4 per cent) may be attributable to reaction from cystoscopy and ureteral catheterization, even though the time from first manipulation to urine collection was in all instances over 60 minutes, or to discomfort from the prolonged recumbent position.

Hix (11) has demonstrated that unilateral trauma to the exteriorized ureters in dogs results in unilateral and ipsilateral reduction in GFR and RPF. We have noted that within a few minutes after catheterization the urine flow was occasionally reduced and remained so for five to ten minutes. This usually occurred at a time when urine flow was initially low and technical difficulty in ureteral catheterization had been encountered.

Differences between the two kidneys in sodium, solute and water excretion during hydropenia and before infusion of test substances were generally of the same order as those present later in the test period (Table V). In 2 (C.A., I.F.) of 13 observations, there were disparities in the basal excretion of sodium, solute and water which were not confirmed during the infusion of inulin and $\mathrm{PAH}$ in saline or water administered at a rate of $2 \mathrm{ml}$ per minute. It is possible that these disparities are

4 GFR, $\mathrm{R}=55.6, \mathrm{~L}=58.1 \mathrm{ml}$ per minute; $\mathrm{RPF}, \mathrm{R}=$ 256, $\mathrm{L}=268 \mathrm{ml}$ per minute; $T \mathrm{~m}_{\mathrm{PAB}}, \mathrm{R}=43.0, \mathrm{~L}=45.0$ $\mathrm{mg}$ per minute; $\mathrm{U}_{\mathrm{Na}} \mathrm{V}, \mathrm{R}=0.12, \mathrm{~L}=0.13 \mathrm{mEq}$ per minute; $\mathrm{U}_{\text {osm }} \mathrm{V}, \mathrm{R}=0.42, \mathrm{~L}=0.44 \mathrm{mOsm}$ per minute. 


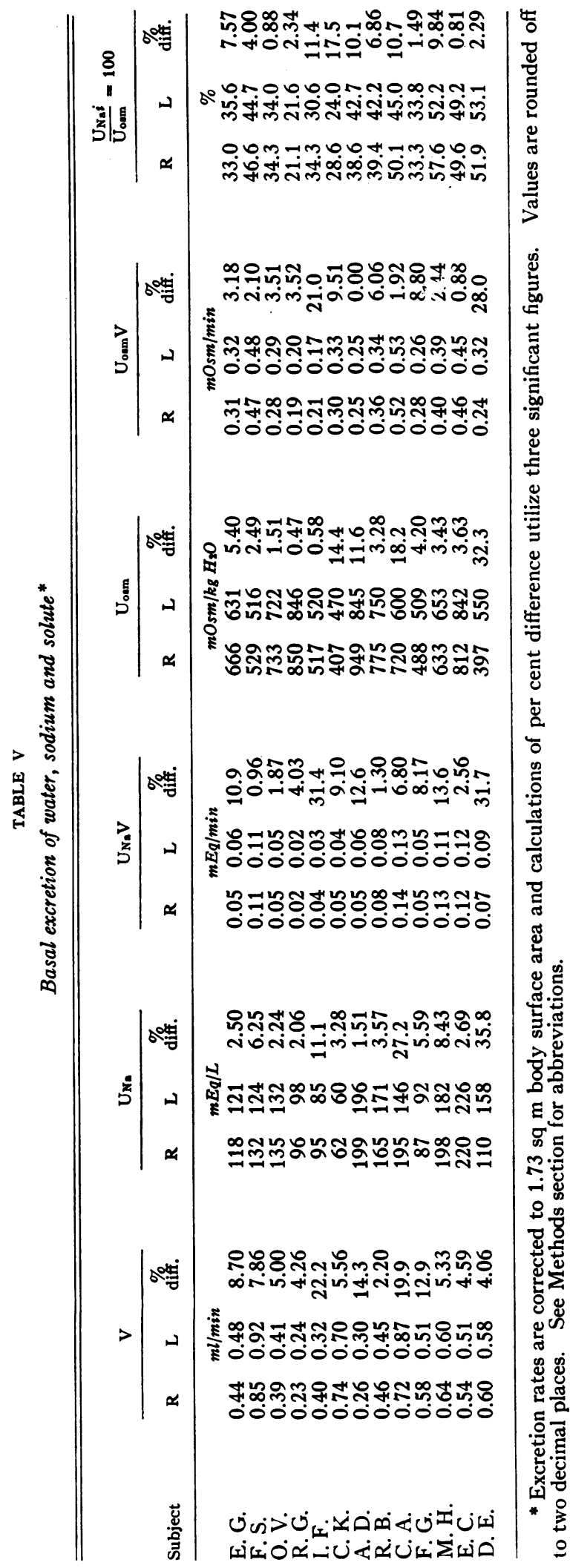

the result of a temporary reflex disturbance or an error in urine collection. Our data indicate, however, that gross changes in hemodynamic function do not occur in normal man following ureteral catheterization.

\section{SUMMARY AND CONCLUSIONS}

1. Observations were made on the functional capacity of the separate kidneys in 21 subjects free of cardiovascular renal disease.

2. Hemodynamics, maximal tubular excretory capacity for $p$-aminohippurate, and sodium, solute and water excretion of the separate kidneys in normal man are comparable. Functional differences in excess of 15 per cent are abnormal on the basis of the present observations. Disparities of function in apparently normal individuals probably represent extremes of normal variation or unidentified renal disease.

3. The functional data confirm the anatomic observations of the predominance of the left kidney.

4. Ureteral catheterization does not induce gross renal hemodynamic changes in normal man. The relative differences between the two kidneys in respect to sodium, solute and water excretion are not altered by the infusion of inulin and $p$-aminohippurate administered at $2 \mathrm{ml}$ per minute.

\section{REFERENCES}

1. Baldwin, D. S., Hulet, W. H., Biggs, A. W., Gombos, E. A., and Chasis, H. Renal function in the separate kidneys of man. II. Hemodynamics and excretion of solute and water in essential hypertension. J. clin. Invest. 1960, 39, 000.

2. Chasis, H., and Redish, J. Effective renal blood flow in the separate kidneys of subjects with essential hypertension. J. clin. Invest. 1941, 20, 655.

3. Smith, H. W. Principles of Renal Physiology. New York, Oxford University Press, 1956.

4. Goldring, W., and Chasis, H. Hypertension and $\mathrm{Hy}-$ pertensive Disease. New York, Commonwealth Fund, 1944.

5. Smith, H. W., Finkelstein, N., Aliminosa, L., Crawford, B., and Graber, M. The renal clearances of substituted hippuric acid derivatives and other aromatic acids in dog and man. J. clin. Invest. 1945, 24, 388.

6. Johlin, J. M. The freezing point determination of physiological solutions. The usual errors and their elimination. J. biol. Chem. 1931, 91, 551.

7. Hall, R. E., and Sherrill, M. S. Freezing-point 
lowerings of aqueous solutions in National Research Council, International Critical Tables, E. W. Washburn, Ed. New York, McGraw-Hill, 1928, p. 254. 8. Snedecor, G. W. Statistical Methods Applied to Experiments in Agriculture and Biology, 5th ed. Ames, The Iowa State College Press, 1956.

9. DeLeon, W., Garcia, A., and DeJesus, P. I. Normal weights of visceral organs in adult Filipinos. Philippine J. Sci. 1933, 52, 111.

10. Möell, $H$. Size of normal kidneys. Acta radiol. (Stockh.) 1956, 46, 640.

11. Hix, E. L. Uretero-renal reflex facilitating renal vasoconstrictor responses to emotional stress. Amer. J. Physiol. 1958, 192, 191. 